\title{
MIDDLE EAR PRESSURE VARIATIONS DURING NITROUS OXIDE AND OXYGEN ANAESTHESIA
}

\author{
Luc Perreault, Nicole normandin, Lyne Plamondon, Robert Blain, \\ Pierre Rousseau, Michel Girard and Guy Forget
}

\begin{abstract}
Many authors have reported middle ear pressure variations during inhalation of high concentrations of nitrous oxide. An on-going study on subjects anaesthetized with nitrous oxide and oxygen supplemented with halogens or narcotics and excluding operations on the ear enables us to register three typical curves of middle ear pressure according to the patency of the Eustachian mube. We recorded significant negative middle ear pressures during the recovery period when there was important obstruction of the Eustachian tube.

The presence of a tympanic "neomembrane" due to an old perforation associated with important obstruction of the Eustachian tube could lead to a tympanic perforation that may be unnoticed by the anaesthetist if it is not specifically investigated. In our series, we report one case of tympanic perforation and one case of haemotympanum as examples of such consequences.
\end{abstract}

Key Words: Anaesthetics, Gases, nitrous oxide; Complications, middle ear pressure changes.

Many aUthors have reported changes in middle ear pressure during and after anaesthesia with nitrous oxide and oxygen. For instance, very high positive pressures from $2.45 \mathrm{kPa}$ $\left(250 \mathrm{mmH}_{2} \mathrm{O}\right)$ to $3.92 \mathrm{kPa}\left(430 \mathrm{mmH}_{2} \mathrm{O}\right)$ have been observed by Thomsen et al. ${ }^{1}$ Matz et al. ${ }^{2}$ have illustrated concentration variations of nitrous oxide and nitrogen in alveoli, arterial blood and middle ear during nitrous oxide anaesthesia and illustrated the pressure curve of these gases

Luc Perreault, M.D., Director, Department of Anaesthesia, Maisonneuve-Rosemont Hospital; Assistant Professor, Department of Anaesthesia, School of Medicine, University of Montreal: Nicole Normandin, M.O.A., Assistant Professor, Ecole d'Orthophonie et d'Audiologie, School of Medicine, University of Montreal; Lyne Plamondon, B.Sc., O.A., Research Assistant in Audiology, Ecole d'Orthophonie et d'Audiologie, School of Medicine, University of Montreal: Robert Blain, M.D., Pierre Rousseau, M.D., Michel Girard, M.D., Department of Anaesthesia, Maisonneuve-Rosemont Hospital; Assistant Professors, Department of Anaesthesia, School of Medicine, University of Montreal: Guy Forget, M.D., Director, Department of Oto-Rhino-Laryngology, Maisonneuve-Rosemont Hospital; Assistant Professor, Department of Oto-Rhino-Laryngology, School of Medicine, University of Montreal.

Mailing Address: Luc Perreault, M.D., Department of Anaesthesia, Maisonneuve-Rosemont Hospital, 5415, l'Assomption blvd, Montreal, P.Q. H1T 2M4. in the middle ear according to their concentration. Patterson and Bartlett ${ }^{3}$ showed the changes in the middle ear pressure curve which occurs when the Eustachian tube functions normally. Dueker et al. ${ }^{4}$ studied middle ear gas exchange in the cat in isobaric counter-diffusion and found that nitrous oxide diffuses into the middle ear through mucosal blood vessels and across the tympanic membrane, causing increase in volume of gas and pressure in the middle ear, and subsequent venting through the Eustachian tube.

Some authors observed negative pressure developing after elimination of nitrous oxide. ${ }^{5,6}$ Important changes in middle ear pressure may lead to problems of ear function such as transitory loss of hearing, ${ }^{6,7}$ haemotympanum, luxaion of the ossicular system, tympanic rupture, ${ }^{8}$ serous otitis and displacement of tympanic graft after tympanoplasty.

This diffusion phenomenon may also be seen in any gaseous cavity of the body. Munson ${ }^{10}$ demonstrated that nitrous oxide diffused into the gastro-intestinal tract, peritoneum, pneumothorax and intracranial cavities, ${ }^{11}$ with an increase in size and/or pressure during anaesthesia for these closed compliant and non-compliant cavities.

Our main interest in this phenomenon came from a study on the tympanic graft under nitrous

Can. Anaesth. Soc. J., vol. 29, no. 5, September 1982 
oxide and oxygen anaesthesia. This study demonstrated that it was important to investigate a large number of cases to obtain a general view of this phenomenon in the middle ear during general anaesthesia for operations performed on sites other than the ear.

The present on-going study intends first to evaluate the importance of middle ear pressure changes during anaesthesia, second, to establish the pattern of the middle ear pressure variations during, immediately following and one day after anaesthesia and, finally, to find out what factors other than nitrous oxide and oxygen contribute to increases of pressure in the middle ear.

\section{MethodOLOGY}

\section{Subjects}

Twenty-five subjects were selected randomly according to the operative schedule. All patients were over 18 years of age and both male and female patients were accepted in the study. The subjects signed an informed consent and it was clearly established that refusal to participate in the study did not alter the course of their medical or surgical treatment.

\section{Anaesthetic Technique}

All subjects received thiopentone $4.5 \mathrm{mg} \cdot \mathrm{kg}^{-1}$ and succinylcholine 1 to $1.5 \mathrm{mg} \cdot \mathrm{kg}^{-1}$ for induction, with or without fentanyl 50 to $100 \mu \mathrm{g}$. After administration of $\mathrm{Flo}_{1} 1$ for a few seconds, the trachea was intubated to prevent any increase in middle ear pressure through the Eustachian tube during controlled ventilation. Anaesthesia was maintained with nitrous oxide 66 per cent and oxygen 33 per cent supplemented with halothane, enflurane or opiates, and curare or pancuronium for neuromuscular blockade. Ventilation was controlled at $10 \mathrm{ml} / \mathrm{kg} 10$ times per minute.

According to the literature, the pressure variation occurs thirty minutes after induction and reaches a plateau during inhalation of nitrous oxide. For this reason, we selected subjects who were under anaesthesia for 60 to 120 minutes.

\section{Equipment and measurement technique}

The Grason-Stadler Middle Ear Analyzer (1723, Version II) was used to assess the middle ear pressure during anaesthesia. This equipment is an impedance bridge currently used in audiology clinics for hearing evaluation and differential diagnosis. It provides three different modes of operation: a sound generator, a sound analyser and an air pressure generator. $A$ probe is introduced into the external auditory canal and a seal is obtained through the use of plastic probe tips. The sound generation section sends a moderately intense pure tone to the ear canal. The sound analysis device electronically measures the changes in the pure tone signal caused by its transmission into the middle ear. The air pressure generator allows for introduction of higher or lower than normal atmospheric pressure into the ear canal. Tympanograms are the graphic representation of the mobility of the tympano-ossicular system under different degrees of water pressure. When equilibration between atmospheric pressure and middle ear pressure is achieved, the peak of the tympanogram is at $0 \mathrm{kPa}$. This pressure balance system permits quantification of pressure in the middle ear by observation of the tympanogram peak pressure points. The validity and reliability of such a device is high as evidenced by a study of Eliachar and Northern ${ }^{12}$ in which pressure chamber correlates highly with pressure peak tympanometry.

\section{Procedure}

The day before the operations all subjects had a complete ear examination, including microscopic examination of the tympanum. In the audiology department, audiograms by air and bone conduction, impedance measurement and speech tests were done.

On the day of operation, preoperative baseline guidelines included the case history of the hearing function and objective impedance measurement including tympanogram, static impedance measurement, Eustachian tube test using the inflation-deflation technique of Williams, ${ }^{13}$ measurement of stapedial reflex level when possible and measurement of decrease of stapedial reflex when possible.

\section{REsults}

The analysis of the curves of three subjects will permit us to discuss the importance of the increased pressure in the middle ear, to evaluate the time course of the pressure variation and the relationship of these two first results with preoperative baseline measurement of Eustachian tube function.

As can be seen in figures 1, 3 and 4, the three curves representing pressure variation during operation have a saw-tooth shape with rises and falls in the middle ear pressure. 
NORUAL CURVE

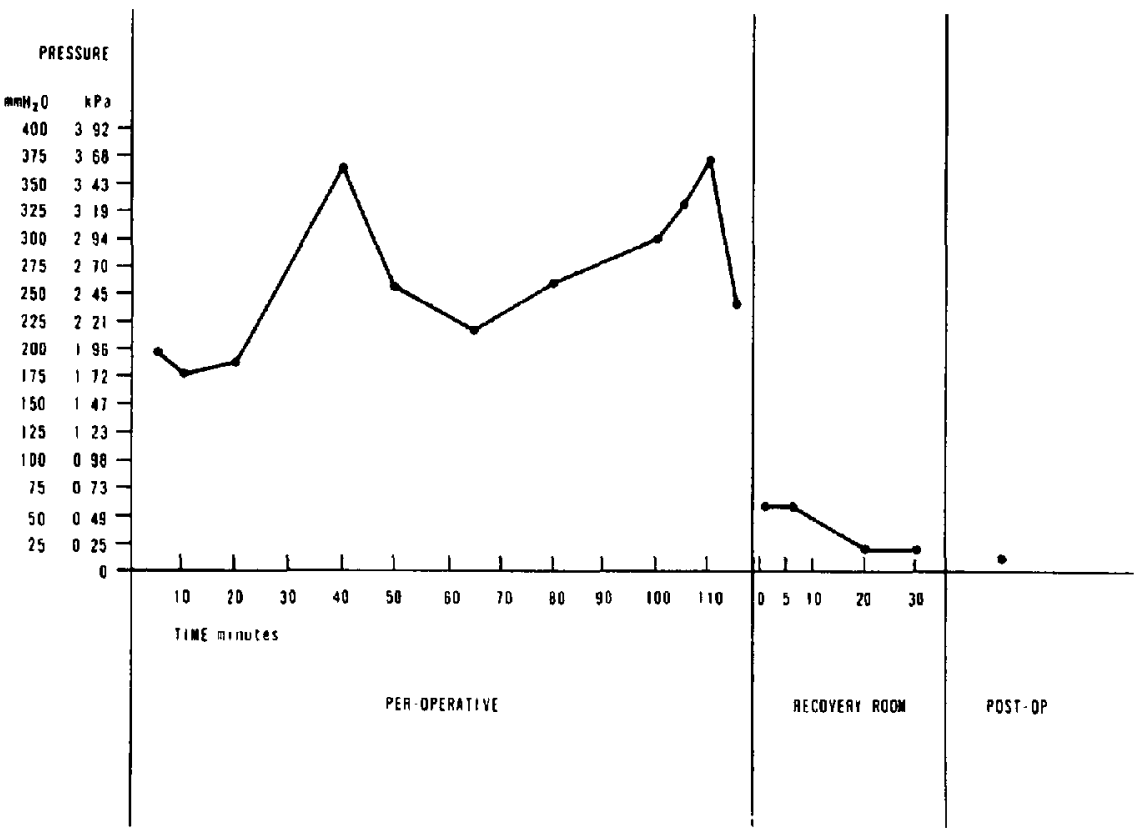

Figure 1 Time course of middle ear pressure variations in patient no 10. Rises and falls in pressure represent gradual diffusion of nitrous oxide in the middle ear and sudden venting through the Eustachian tube. Postoperative middle ear pressure is normal.

In the first curves (subject 10), the pressure increase reaches the level of $3.68 \mathrm{kPa}$ $\left(375 \mathrm{mmH}_{2} \mathrm{O}\right.$ ) during the first thirty minutes. The rate of elevation of middle ear pressure is about $0.09 \mathrm{kPa}\left(9 \mathrm{mmH}_{2} \mathrm{O}\right)$ per minute. This value has been found to be the same by Davis et al. ${ }^{6}$ The decrease in pressure after thirty minutes represents the opening pressure of the Eustachian tube, which for this patient is about $3.68 \mathrm{kPa}\left(375 \mathrm{mmH}_{2} \mathrm{O}\right)$. The minimum pressure obtained during operation is about $2.20 \mathrm{kPa}$ $\left(225 \mathrm{mmH}_{2} \mathrm{O}\right)$ which is not the level of normal atmospheric pressure encountered in the middle ear in an unanaesthetized subject. Subsequent diffusion of nitrous oxide during anaesthesia shows further increase in middle ear pressure. On cessation of inhalation of nitrous oxide there was a progressive decrease of pressure in the middle ear during the following thirty minutes, down to the preoperative level. This level stays the same for the following hours and the day after anaesthesia. This finding is consistent with the classical description of changes in middle ear pressure during nitrous oxide anaesthesia. It is consistent also with the normal Eustachian tube function found at the preoperative level as illustrated by the tympanograms of figure 2 . In this figure it is shown that the middle ear can adequately equilibrate a positive and a negative pressure delivered artificially into the external auditory canal by the impedance bridge.

The second curve (subject 3 ) is seen in figure 3. The pressure rises higher than in the first case. It reaches the maximum level of pressure recorded on the impedance bridge, i.e. $3.92 \mathrm{kPa}$ $\left(400 \mathrm{mmH}_{2} \mathrm{O}\right)$. The decrease in pressure after thirty minutes represents the opening pressure of the Eustachian tube which for this patient is about $2.70 \mathrm{kPa}\left(275 \mathrm{mmH}_{2} \mathrm{O}\right)$. In the recovery room, the pressure remains higher and for a longer period than in the first case. The day after the operation, the pressure is back to normal.

The last curve (subject 17) presented in figure 4 shows a very high increase of middle ear pressure in less than thirty minutes. There are also highs and lows on the curve and, at a certain point, the pressure reaches a level higher than $3.92 \mathrm{kPa}\left(400 \mathrm{mmH}_{2} \mathrm{O}\right)$. The critical feature of this curve is the presence of important negative pressure of minus $4.9 \mathrm{kPa}\left(-500 \mathrm{mmH}_{2} \mathrm{O}\right)$ sixty-five minutes after the interruption of the anaesthetic agent. The Eustachian tube test in 


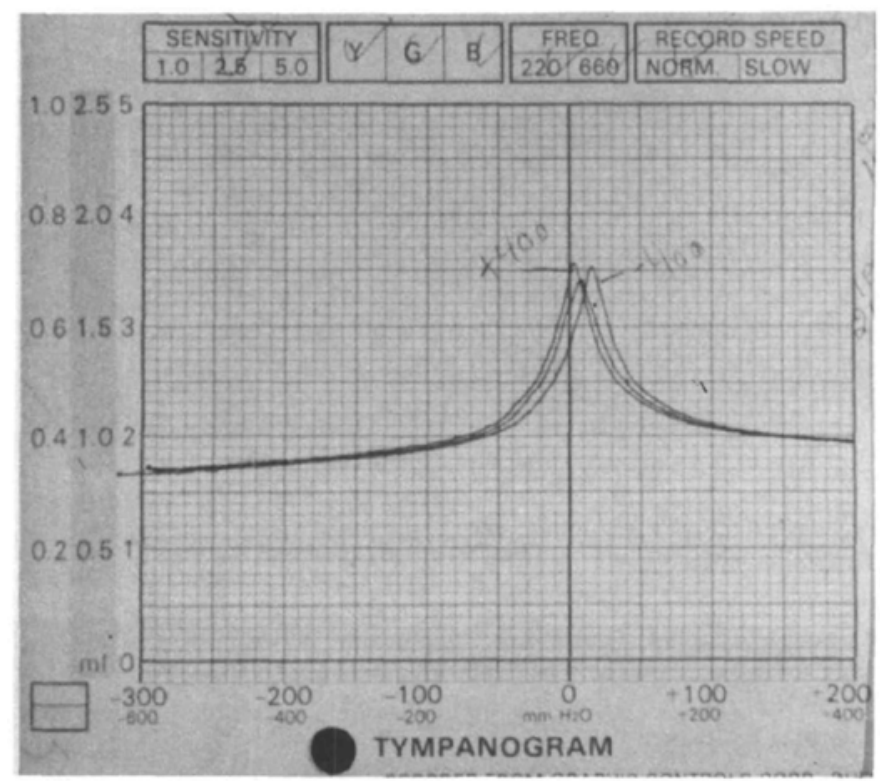

FIGURE 2 Preoperative baseline level of Eustachian tube patency in patient no 10. The three tympanograms represent complete equilibration for positive and negative middle ear pressure.

PARTIAL OESTRUCTION OF EUSTACHIAN TUBE

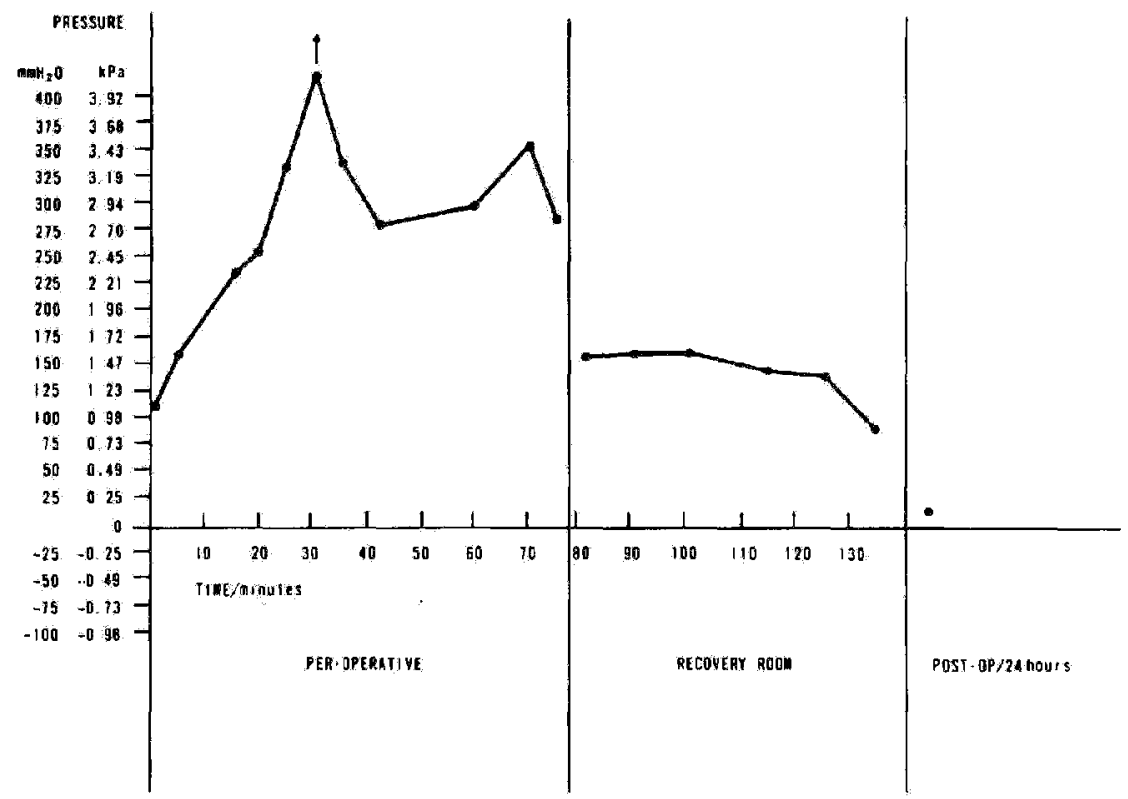

FIGURE 3 Time course of middle ear pressure variations in patient no 3 . Rises and falls in pressure represent gradual diffusion of nitrous oxide in the middle ear and sudden venting through the Eustachian tube. Arrows mean pressure values higher than $3.92 \mathrm{kPa}\left(400 \mathrm{mmH}_{2} \mathrm{O}\right)$. Postoperative middle ear pressure comes back to normal after 24 hours. 


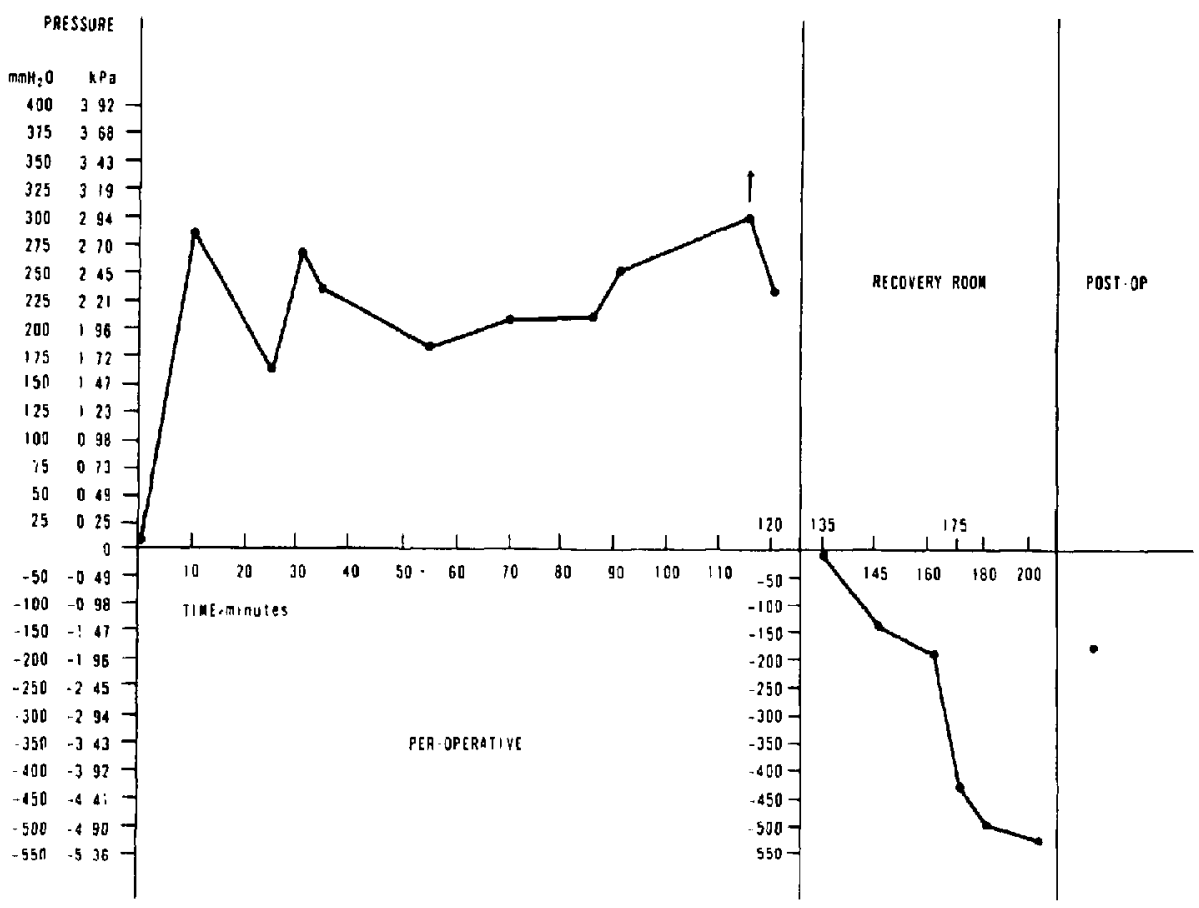

Figure 4 Time course of middle ear pressure variations in patient no 17. Rises and falls in pressure represent gradual diffusion of nitrous oxide in the middle ear and sudden venting through the Eustachian tube. Arrows mean pressure values higher than $3.92 \mathrm{kPa}\left(400 \mathrm{mmH}_{2} \mathrm{O}\right)$. Postoperative middle ear pressure is negative in the recovery room and does not come back to normal even 24 hours after operation.

figure 5 shows that the three curves are perfectly superimposed. According to Williams technique, this is consistent with a completely obstructed Eustachian tube. For this patient, there was then no possibility of opening of the Eustachian tube to counteract the effect of diffusion during administration and elimination of nitrous oxide.

\section{Discussion}

This study shows important variations of positive and negative pressure in the middle ear cavity. This phenomenon is explained by the important pressure gradient built up by the high inspired concentration of nitrous oxide, the difference in blood solubility of nitrous oxide compared to nitrogen and the lack of an important ear/blood pressure gradient for nitrogen. The result is an excess of gas in the noncompliant middle ear cavity.

In our clinical experierice, we must attribute a major importance to the possibility of venting gases in and out the middle ear through the Eustachian tube. At the time of elimination of nitrous oxide the patient is recovering and regains the swallowing reflex. This opens the Eustachian tube and permits efficient equilibration of middle ear pressure during the recovery period. This is the reason why the pressure should be at a normal atmospheric level in the middle ear.

It is possible to make a relationship between the integrity of Eustachian tube function and the variation of middle ear pressure during nitrous oxide and oxygen anaesthesia. Complete obstruction of the Eustachian tube may generate important negative pressure during recovery from anaesthesia.

Subjects having an obstruction of the Eustachian tube and the presence of a tympanic "neomembrane" present an increased risk for the use of nitrous oxide. If the tympanic membrane is weakend by the presence of a "neomem- 


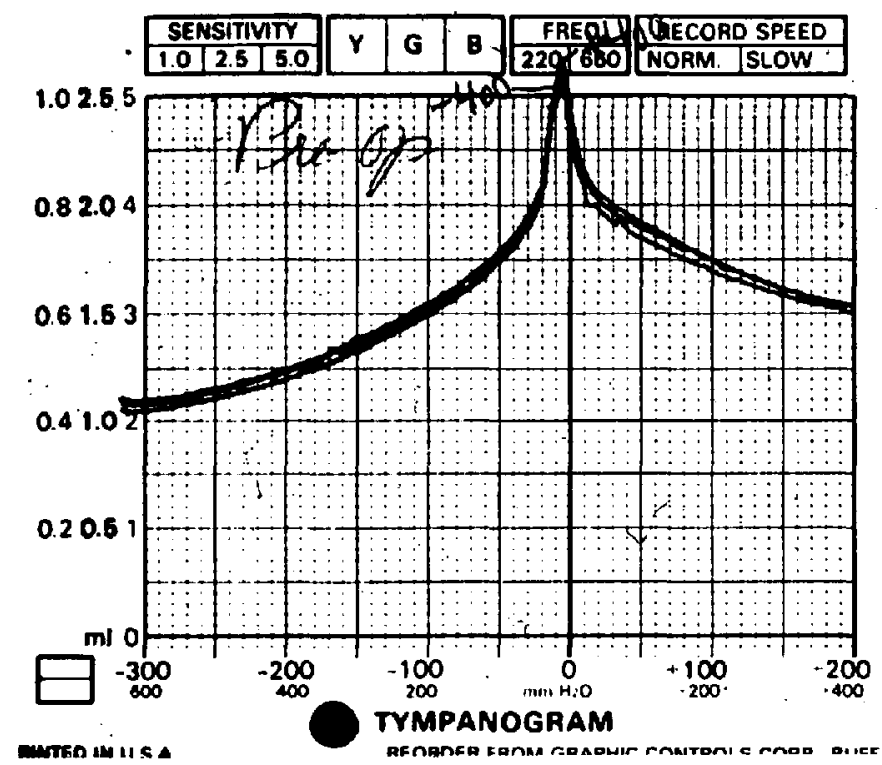

FIGURE 5 Preoperative baseline level of Eustachian tube patency in patient no 17. The three tympanograms are superimposed, meaning no equilibration of negative and positive pressures in the middle ear.

brane" it may rupture under the stress of this negative pressure. These accidents surely happen without being recognized by anaesthetists and could lead to more important complications.

In our series of twenty-five patients, two subjects had major complications in the ear following inhalation of nitrous oxide: one had a spontaneous tympanic rupture on one side and the other developed a haemotympanum. Both were discovered in the recovery room immediately after anaesthesia by sudden change in the shape of the tympanometric curves. It is interesting to note that both subjects had preoperative complete obstruction of the Eustachian tube, with the presence of a tympanic "neomembrane", and both developed significant negative pressure during the recovery period.

The severe negative pressure recorded during the recovery period could cause an irritation of the vestibular system leading to nausea and vomiting. The intense traction on round window membrane may be responsible for the stimulation of vestibular innervation. We are investigating this phenomenon in our department.

\section{CONCLUSION}

The administration of high concentrations of nitrous oxide is not without danger for hearing function. The important variations in middle ear pressure may lead to loss of hearing caused by luxation of the ossiculo-tympanic system and tympanic rupture. We feel that the preanaesthetic visit should include a questionnaire on previous ear pathology. With a previous history of ear discharge, the anaesthetist should keep in mind the presence of a scar on the tympanum with reduced resistance to changes in middle ear pressure. A history of previous surgery in the middle ear increases the risk of complication. We believe that nitrous oxide should be avoided in these patients for any kind of surgery. It should also be eliminated for all ear surgery including tympanoplasty, stapedectomy, ossicular reposition and mastoidectomy.

Anaesthesia in these cases should respect normal physiology and we should use a mixture of air and oxygen as a vaporizing vehicle for halogenated agents to eliminate the problem of diffusion encountered with nitrous oxide.

\section{ACKNOWLEDGEMENT}

We want to thank Christiane Côté and Louise Juneau, research nurses, for their collaboration in this study. We also thank misses Renée Ledoux and Thérèse Fafard, Clinical Audiolo- 
gists, for having performed clinical hearing evaluation.

This work has been made possible with a grant of Research funds of University of Montreal.

\section{REFERENCES}

1. Thomsen, K.A., Terkildsen, K. \& Arnfred, I. Middle ear pressure variations during anesthesia. Arch. Otolaryngol. 82: 609-611 (1965).

2. Matz, G.J., Rattengorg, C.G. \& Holaday, D.A. Effects of nitrous oxide on middle ear pressure. Anesthesiology 28: 948-950 (1967).

3. Patterson, M.E. \& Bartiett, P.C. Hearing impairment caused by intratympanic pressure changes during general anaesthesia. Laryngoscope 86: 399-404 (1976).

4. DUEKer, C.W., LAMberTSEN, C.J., Rosowski, J.J. \& SAunders, J.C. Middle ear gas exchange in isobaric counterdiffusion. J. Appl. Physiol. 47: 1239-1244 (1979).

5. OSTFELD, E. \& BLONDER, J. et al. Middle ear gas composition during nitrous oxide-oxygen ventilation. Ann. Otolaryngol. 89: 165-167 (1980).

6. Davis, I., MOORE, J.R.M., \& LAHIRI, S.K. Nitrous oxide and middle ear. Anesthesia 34: 147-151 (1979).
7. WaUn, J.E., Sweitzer, R.S. \& Hamilton, W.K. Effect of nitrous oxide on middle ear mechanics and hearing acuity. Anesthesiology 28: 846-850 (1967).

8. Owens, W.D., Gustave, F. \& Sclaroff, a Tympanic membrane rupture with nitrous oxide anesthesia. Anesth. Analg. 57:283-286 (1978).

9. Perreault, L., Rousseau, P., Garneau, J.F. et al. Problème de la diffusion gazeuse dans l'oreille moyenne au cours de l'anesthésie pour tympanoplastie. Canad. Anaesth. Soc. J. 28: 136-140 (1981).

10. Munson, E.S. Transfer of nitrous oxide into body air cavities. Br. J. Anaesth. 46: 202-209 (1974).

11. Paul, W.L., Munson, E.S. \& Maniscalco, J.E. Cerebrospinal fluid pressure during $\mathrm{O}_{2}$ encephalograpy and $\mathrm{N}_{2} \mathrm{O}$ inhalation. Anesth. Analg. 55: 849-851 (1976).

12. Eliachar, I. \& Northern, J.L. Studies in tympanometry: Validation of the present technique for determining intra-tympanic pressures through the intact eardrum. Laryngoscope 84 : 247-255 (1974).

13. Williams, P.S. A tympanometric pressure swallow test for asessment of Eustachian tube function. Ann. Otolaryngol. 84: 339-343 (1975).

\section{RESUME}

Plusieurs auteurs ont rapporté, à date, des variations de la pression de l'oreille moyenne au cours de l'inhalation de concentrations cliniques de protoxyde d' azote. Une étude entreprise chez des sujets subissant une anesthésie au protoxyde d'azote-oxygène additionnée de narcotiques ou de substance halogénée, nous permet de mettre en évidence trois types de courbes de pression intra-auriculaire selon l'état de perméabilité de la trompe d'Eustache.

Il est possible d'observer d'importantes pressions négatives dans l'oreille moyenne durant la période de réveil chez les malades qui ont une obstruction complète de la trompe d'Eustache.

La présence de cicatrice d'anciennes perforations du tympan associée à une obstruction importante de la trompe d'Eustache constitue un facteur de risque significatif pouvant conduire à une perforation tympanique qui peut passer inaperçue si elle n'est pas recherchée spécifiquement. Nous rapportons, dans notre courte série, un cas de perforation tympanique et un cas d'hémotympan. 